\title{
Suicide Attempts in US Veterans with Chronic Headache Disorders: A I0-Year Retrospective Cohort Study
}

\author{
X Michelle Androulakis $\mathbb{D}^{1-4, *}$ \\ Siyuan Guo $\mathbb{1 D}^{2, *}$ \\ Jiajia Zhang ${ }^{2}$ \\ Jason Sico ${ }^{5,6}$ \\ Peter Warren' \\ Alec Giakas (iD ${ }^{3}$ \\ Xiaoming $\mathrm{Li}^{2}$ \\ B Lee Peterlin ${ }^{7}$ \\ Roy Mathew ${ }^{1,3}$ \\ Deborah Reyes'
}

'Department of Neurology, Columbia VA Healthcare System, Columbia, SC, USA;

${ }^{2}$ Arnold School of Public Health,

University of South Carolina, Columbia,

SC, USA; ${ }^{3}$ School of Medicine, University

of South Carolina, Columbia, SC, USA;

${ }^{4}$ Headache Centers of Excellence

Program, US Department of Veterans

Affairs, Columbia, SC, USA; ${ }^{5}$ Department

of Neurology, Yale School of Medicine,

New Haven, CT, USA; ${ }^{6}$ Headache

Centers of Excellence Program, US

Department of Veterans Affairs, West

Haven, CT, USA; ${ }^{7}$ Pennsylvania Headache

Center, Camp Hill, PA, USA

*These authors contributed equally to this work
Correspondence: $X$ Michelle Androulakis Email Xiao.androulakis@va.gov
Objectives: A large-scale retrospective analysis of veterans with chronic pain was conducted to examine (1) the annual incidence of suicide attempts (SA) in veterans with chronic headache and other chronic pain conditions, and (2) the risk of SA in men and women with chronic headache and chronic headache concurrent with traumatic brain injury (TBI) as compared to non-headache chronic pain.

Methods: This retrospective study $(\mathrm{N}=3,247,621)$ analyzed National Veterans Affair Health Administrative data of patients diagnosed with chronic head, neck, back and other chronic pain from 2000 to 2010. Multivariable Poisson regression was used to explore the relative risks of SA in veterans with chronic headache and chronic headache concurrent with TBI as stratified by sex.

Results: Veterans with chronic headaches had the highest annual incidence of SA (329 to 491 per 100,000) each year among all identified types of chronic pain conditions. Compared to other non-headache chronic pain, chronic headache is associated with increased risk of SA [men RR (1.48), CI (1.37,1.59); women RR (1.64), CI (1.28,2.09)], after adjusting for demographic factors, TBI, and psychiatric comorbidities. The risk increased further when chronic headache is comorbid with TBI [men RR (2.82), CI (2.60, 3.05); women RR (2.16, CI (1.67-2.78)].

Conclusion: Veterans with chronic headache have a higher risk of SA than those with other chronic pain and women with chronic headache are at a higher risk than men with chronic headache. Chronic headache concurrent with TBI further heightened this risk, especially in men. Our data underscore the importance of identifying specific types of chronic pain in veterans with comorbid TBI and sex disparity associated with SA when targeting suicide prevention measures.

Keywords: headache, migraine, suicide attempt, TBI, veteran

\section{Introduction}

Risk of suicide is higher in a spectrum of neurological diseases, such as stroke, epilepsy, multiple sclerosis, migraine headache, Traumatic Brain Injury (TBI) and other brain disorders, suggesting a complex interplay between the underlying dysfunctional nervous system, comorbid psychiatric disorders, and subjective experiences, such as hopelessness. ${ }^{1-3}$ Chronic headache is the second leading cause of years lived with disability worldwide. ${ }^{4}$ It is a considerable public health problem in the United States, especially in veterans with TBI. Having a history of TBI increases risk for suicidal ideation, ${ }^{5}$ suicide attempts $(\mathrm{SA})^{6,7}$ and death by suicide. ${ }^{8-10}$ Specifically, an 
increased risk of suicide has been reported in veterans with TBI and retired athletes with chronic traumatic encephalopathy. $^{9,10}$ Headaches, arthritis, and back pain have lifetime rates of SA that range from $5 \%$ to $14 \%$ in the civilian population and commonly result in chronic pain. ${ }^{11}$ Several studies have shown that experiencing chronic headaches or having chronic pain in general increases the risk for SA as compared to healthy controls. ${ }^{12-18}$ Migraine, the most common subtype of post-traumatic headache attributable to TBI, is associated with increased suicidality. ${ }^{19}$ It is still not known if veterans with chronic headache are at a higher risk of SA than those with other types of chronic pain conditions. Despite the recent advances in new drug and device development, there are limited effective therapeutic options for chronic headache and TBI. Chronic headache and TBI often involve a sense of helplessness and lack of agency, both of which are key factors related to the development of suicidal ideation and subsequent attempts $^{3,20}$ Furthermore, given that headache, especially migraine-like headache, is the most common long-term sequalae of TBI, concurrent chronic headache with TBI could further exacerbate the risk of SA.

The 2019 National Veteran Suicide Prevention Annual Report notes that the incidence of death by suicide among veterans ranged between 17.6 per 100,000 in 2006 and 27.7 per 100,000 in $2017 .^{21}$ One Canadian study using a community survey found that the one-year incidence of $\mathrm{SA}$ in civilian population with chronic pain was 914.3 per $100,000 .^{22}$ However, the annual incidence of SA among veterans with chronic headache and other types of chronic pain conditions is still unknown. ${ }^{23,24}$ Within the civilian population, women have a higher prevalence of chronic pain than men, ${ }^{25}$ and women with migraine have higher headache-related disability and healthcare resource utilization. ${ }^{26}$ While women tend to attempt suicide more often than men, ${ }^{27}$ men have a higher risk of suicide mortality. ${ }^{28,29}$ Currently, there is a paucity of research assessing the role of sex in SA among veterans with chronic headache with or without TBI.

This study aimed to identify the incidence of SA using a national in-patient and outpatient administrative database in veterans with chronic head, neck, back, and other chronic pain conditions from 2001 to 2010, as well as to examine the risk of SA in veterans with chronic headache disorders alone and chronic headache concurrent with TBI as stratified by sex. We hypothesized that 1) chronic headache, especially when concurrent with TBI, would be associated with an increased SA as compared to veterans with other pain conditions, and that 2) this association may differ in men and women. Because of the high prevalence of chronic post-traumatic headache in the veteran population and the under-diagnosis of migraine as well as posttraumatic headache, our research analyzed administrative data of chronic headache disorders. ${ }^{30-34}$

\section{Methods}

\section{Data Source and Study Population}

This retrospective cohort study examined inpatient and outpatient medical records within Veteran Health Administration's (VHA) electronic health records (EHR). The Veteran's Affair Informatics and Computing Infrastructure (VINCI) was used to access the VHA's Corporate Data Warehouse (CDW). The CDW was developed in 2006 to store and integrate inpatient and outpatient health records from multiple clinical centers and systems across the nation to support management, research, and data analytics. ${ }^{35,36}$ We identified the chronic pain cohort by reviewing CDW records between January 1st, 2000 and December 31st, 2010. We identified veterans with at least one chronic pain condition (head, neck, back or other pain conditions) as defined by the International Classification of Diseases, 9th edition (ICD-9) diagnostic codes (Supplementary Table 1). The diagnosis was considered chronic only if a specific pain diagnosis persisted in the chart at least longer than 90 days after the initial diagnosis. A total of $3,247,621$ veterans between the ages of 18 and 95 with chronic head, neck, back and other non-cancer related pain (joint pain, fibromyalgia, reflex sympathetic dystrophy) were included in this study (Figure 1).

\section{Standard Protocol Approvals and Registrations}

The institutional review board of the Columbia Veteran's Affair Health Care System approved this study. The VINCI data accessed complied with the relevant data protection and privacy regulations.

\section{Measures}

Demographics

Demographic variables examined were Sex (male and female), Race (Asian, Black, White, and Other/ Unknown), Ethnicity (Hispanic/Latino, Not Hispanic/ Latino, and Unknown), and Age at the time of the first chronic pain diagnosis. 


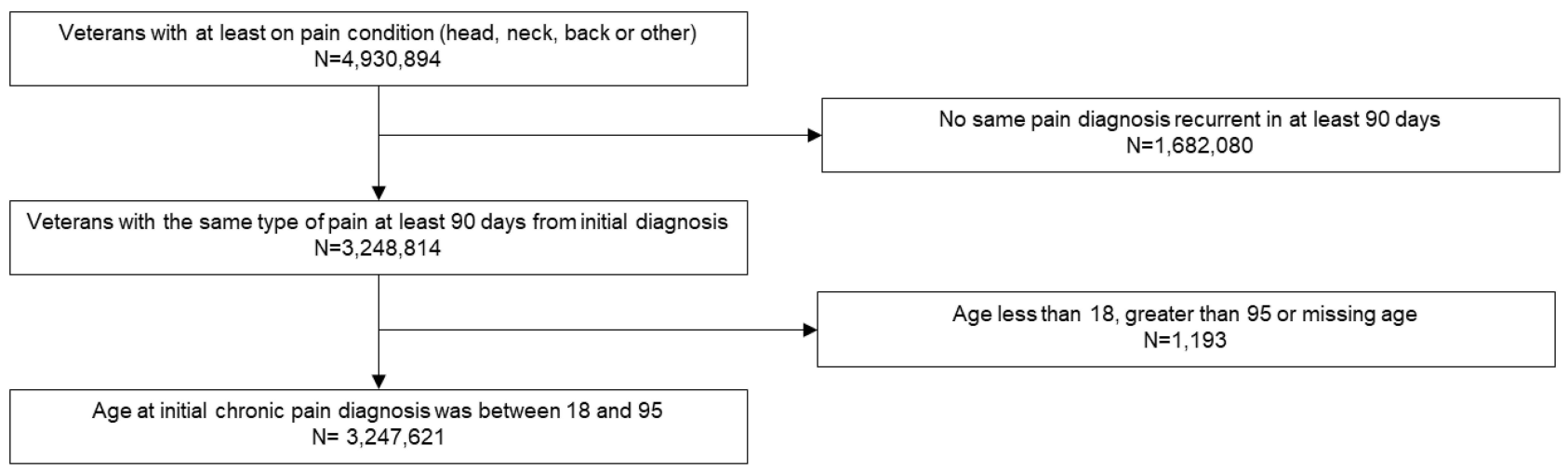

Figure I Cohort selection flow.

\section{Suicidal Attempts}

SA following the first chronic pain diagnosis were identified with ICD-9 codes that specified intent of self-harm (Supplementary Table 1). Annual SA incidence was calculated by the ratio of total number of patients with new SA to total patients with specific chronic pain condition that year. The total number of SA after the first chronic pain diagnosis between the years 2000 and 2010 was calculated for each participant.

\section{Traumatic Brain Injury (TBI)}

TBI was identified among veterans with chronic pain, including all levels of TBI severity using ICD-9 codes (Supplementary Table 1).

\section{Psychiatric Comorbidity}

The psychiatric comorbidities were identified among veterans with chronic pain conditions as following: Depression, Anxiety, Adjustment Disorder, Antisocial Personality Disorder, Attention Deficit Hyperactivity Disorder (ADHD), Bipolar Disorder, Borderline Personality Disorder, Delusional Disorder, Dependent Personality Disorder, Narcissistic Personality Disorder, Obsessive-Compulsive Disorder (OCD), Posttraumatic Stress Disorder (PTSD), Schizoaffective Disorder and Schizophrenia.

\section{Statistical Analysis}

Annual Incidence Rates

Annual incidence rates of SA per 100,000 were calculated for each chronic pain condition from 2001 to 2010. Primary analysis was conducted by examining the differences in annual incidence rates in chronic pain patients with headache, back pain, neck pain or other pain.

\section{Regression Analysis}

Multivariable Poisson regression was used to examine the association between chronic headache disorders and the number of SA in the entire cohort, male cohort, and female cohort. Other confounders adjusted were age at the time of the first chronic pain diagnoses, sex, race, ethnicity, the presence of TBI, psychiatric comorbidities, and the interactions of chronic headache with TBI or psychiatric comorbidities. The reference levels of the categorical variables were White for race, and non-Hispanic/Latino for ethnicity. To compare the association of chronic headache and SA between men and women, we further investigated the interaction terms between sex and other covariates. The relative risks (RR) and 95\% confidence intervals (CI) were reported. The significance level of 0.05 was applied to all analyses.

\section{Data Availability Statement}

All the data extraction and analysis were done in Microsoft SQL server, SAS 9.4, and SAS enterprise Guide 7.1 (SAS Institute, Cary, NC, USA) through VINCI.

\section{Results}

\section{Demographics}

In this cohort of participants with different types of chronic pain, $14.19 \%$ of them had chronic headache, $14.90 \%$ had chronic neck pain, $59.30 \%$ had chronic back pain and $60.28 \%$ had other types of chronic pain within the calendar years of 2000 to 2010 (Table 1). Non-specific headache diagnosis and migraine were the most common types of headache disorders (Table 2). Depression, PTSD, and adjustment disorder were the most common psychiatric comorbid conditions (Table 1). 
Table I Demographics and Clinical Characteristics of All Participants

\begin{tabular}{|c|c|c|c|c|c|c|c|c|}
\hline & \multicolumn{2}{|c|}{$\begin{array}{c}\text { Headache } \\
(n=460,843)\end{array}$} & \multicolumn{2}{|c|}{$\begin{array}{c}\text { Back Pain } \\
(n=1,925,694)\end{array}$} & \multicolumn{2}{|c|}{$\begin{array}{c}\text { Neck Pain } \\
(n=483,839)\end{array}$} & \multicolumn{2}{|c|}{$\begin{array}{l}\text { Other Pain } \\
(n=1,957,747)\end{array}$} \\
\hline & $\mathbf{n}$ & $\%$ & $\mathbf{n}$ & $\%$ & $\mathbf{n}$ & $\%$ & $\mathbf{n}$ & $\%$ \\
\hline \multicolumn{9}{|l|}{ Sex } \\
\hline $\mathrm{F}$ & 86,321 & 18.73 & 148,339 & 7.70 & 47,507 & 9.82 & 137,297 & 7.01 \\
\hline$M$ & 374,522 & 81.27 & I,777,355 & 92.30 & 436,332 & 90.18 & $\mathrm{I}, 820,450$ & 92.99 \\
\hline \multicolumn{9}{|l|}{ Age of Onset } \\
\hline $18-25$ & 14,695 & 3.19 & 33,961 & 1.76 & 3,915 & 0.81 & $\mathrm{II}, 772$ & 0.60 \\
\hline $26-35$ & 54,156 & 11.75 & II 3,397 & 5.89 & 22,479 & 4.65 & 58,878 & 3.01 \\
\hline $36-45$ & 72,760 & 15.79 & 195,949 & 10.18 & 52,021 & 10.75 & 134,100 & 6.85 \\
\hline $46-55$ & 107,073 & 23.23 & $4 \mid 4,238$ & 21.51 & 119,996 & 24.80 & 345,716 & 17.66 \\
\hline $56-65$ & 89,831 & 19.49 & 452,578 & 23.50 & 131,565 & 27.19 & 467,624 & 23.89 \\
\hline $65-95$ & 122,328 & 26.54 & $7|5,57|$ & 37.16 & 153,863 & 31.80 & 939,657 & 48.00 \\
\hline \multicolumn{9}{|l|}{ Race } \\
\hline Asian & 3,062 & 0.66 & $\mathrm{II}, 424$ & 0.59 & 2,900 & 0.60 & 88,23 & 0.45 \\
\hline Black or African & 91,138 & 19.78 & 303,770 & 15.77 & 82,276 & 17.00 & 293,803 & 15.01 \\
\hline American & & & & & & & & \\
\hline Other/unknown & 56,586 & 12.28 & 285,334 & 14.82 & 56,958 & 11.78 & 319,774 & 16.34 \\
\hline White & 310,057 & 67.28 & $1,325,166$ & 68.81 & 341,705 & 70.62 & $\mathrm{I}, 335, \mathrm{I} 47$ & 68.20 \\
\hline \multicolumn{9}{|l|}{ Ethnicity } \\
\hline Hispanic or latino & 26,126 & 5.67 & 101,449 & 5.27 & 25,781 & 5.33 & 88,001 & 4.50 \\
\hline Not Hispanic or latino & 403,953 & 87.66 & $1,646,108$ & 85.48 & 427,985 & 88.46 & 1653,139 & 84.44 \\
\hline Unknown & 30,764 & 6.68 & 178,137 & 9.25 & 30,073 & 6.22 & 216,607 & 11.06 \\
\hline $\mathrm{TBI}$ & 51,878 & 11.26 & $|3|, 720$ & 6.84 & $4 I, 120$ & 8.50 & 114,868 & 5.87 \\
\hline \multicolumn{9}{|l|}{ Psychiatric comorbidities } \\
\hline Depression & 260,047 & 56.43 & 856,071 & 44.46 & 253,325 & 52.36 & 765,002 & 39.08 \\
\hline Adjustment disorder & 100,222 & 21.75 & 308,310 & 16.01 & 97,587 & 20.17 & 271,972 & 13.89 \\
\hline $\begin{array}{l}\text { Antisocial personality } \\
\text { disorder }\end{array}$ & 7,552 & 1.64 & 22,200 & 1.15 & 6,970 & $\mathrm{I} .44$ & $|8,03|$ & 0.92 \\
\hline ANXIETY & 43,417 & 9.42 & 128,942 & 6.70 & 42,347 & 8.75 & $1 \mid 4,753$ & 5.86 \\
\hline ADHD & 7,209 & 1.56 & 18,777 & 0.98 & 6,048 & 1.25 & 13,616 & 0.70 \\
\hline Bipolar disorder & 44,612 & 9.68 & 123,508 & 6.41 & 38,876 & 8.03 & 102,773 & 5.25 \\
\hline $\begin{array}{l}\text { Borderline personality } \\
\text { disorder }\end{array}$ & 12,004 & 2.60 & 23,419 & 1.22 & 8,393 & 1.73 & 19,299 & 0.99 \\
\hline Delusional disorder & 5,172 & 1.12 & 15,663 & 0.81 & 4,829 & 1.00 & 14,596 & 0.75 \\
\hline $\begin{array}{l}\text { Dependent personality } \\
\text { disorder }\end{array}$ & $3,4 I I$ & 0.74 & 8,644 & 0.45 & 2,875 & 0.59 & 7,539 & 0.39 \\
\hline $\begin{array}{l}\text { Narcissistic personality } \\
\text { disorder }\end{array}$ & 2,954 & 0.64 & 8,306 & 0.43 & 2,872 & 0.59 & 7,208 & 0.37 \\
\hline OCD & 7,028 & 1.53 & 17,988 & 0.93 & 5,934 & 1.23 & 15,526 & 0.79 \\
\hline PTSD & 145,154 & 31.50 & 424,878 & 22.06 & $|3|, 723$ & 27.22 & 363,268 & 18.56 \\
\hline Psychotic disorder & 34,924 & 7.58 & 110,150 & 5.72 & 31,115 & 6.43 & 112,009 & 5.72 \\
\hline Schizoaffective disorder & 12,896 & 2.80 & 38,152 & 1.98 & 11,101 & 2.29 & 33,882 & 1.73 \\
\hline Schizophrenia & 19,616 & 4.26 & 63,040 & 3.27 & 17,826 & 3.68 & 58,552 & 2.99 \\
\hline
\end{tabular}

Abbreviations: PTSD, posttraumatic stress disorder; OCD, obsessive compulsive disorder; ADHD, Attention Deficit Hyperactivity Disorder.

\section{Annual Incidence of Suicide Attempts}

Over the past decade, the incidence of SA was consistently the highest for chronic headaches, followed by chronic neck pain, chronic back pain and other chronic pain (Figure 2). It is noted that the highest incidence of SA, 491 per 100,000, was identified among veterans with chronic headache in 2005. 
Table 2 The Distribution of Different Types of Chronic Headaches Among Participants

\begin{tabular}{|l|c|c|c|}
\hline & $\mathbf{N}$ & $\begin{array}{c}\% \text { In } \\
\text { Headache }\end{array}$ & $\begin{array}{c}\text { \% In All } \\
\text { Cohort }\end{array}$ \\
\hline Migraine & 231,463 & 50.23 & 7.13 \\
Tension headache & 40,482 & 8.78 & 1.25 \\
Trigeminal neuralgia & 23,108 & 5.01 & 0.71 \\
Cluster headache & 3,813 & 0.83 & 0.12 \\
Post traumatic & 3,128 & 0.68 & 0.10 \\
headache & 369,200 & 80.11 & 11.37 \\
$\begin{array}{l}\text { Other non-specific } \\
\text { headache }\end{array}$ & & \\
\hline
\end{tabular}

\section{Results from Poisson Regression}

Asian veterans had a higher risk of SA in both sex [men RR (1.43), CI (1.28,1.59); women RR (2.93), CI (2.41, $3.51)$ ] compared to white patients among veterans with all chronic pain conditions. The impact of ethnicity on SA is different between men and women with chronic pain: compared to non-Hispanic/Latino patients, Hispanic/ Latino veterans had a higher risk [RR (1.211), CI (1.10, 1.33)] among women; and lower risk [RR (0.86), CI (0.83, 0.89)] among men. Even though men are at a higher risk of SA in the entire cohort of chronic pain participants
(Table 3), men with chronic headache disorders are at a lower risk of SA than women [RR (0.90), CI $(0.70,1.17)]$.

Chronic headache disorders are associated with an increased risk of SA, which was slightly higher in women [RR (1.64), CI $(1.28,2.09)]$ than in men RR (1.48), CI (1.37, 1.59)]. TBI is associated with increased risk in men [RR 1.67 , CI $(1.63,1.71)]$ and women [RR 1.10, CI $(1.01,1.20)]$ (Table 4: without occurrence of headache). Concurrent chronic headache with TBI is associated with an increased SA risk compared to chronic headache or TBI alone in both men and women (Table 4). Men with TBI and headache are at a higher SA risk than women [men RR (2.82) CI (2.60, 3.05), women RR (2.16), CI $(1.67,2.78)]$.

It is worth noting that men with anxiety alone and women with OCD alone have no association with SA risk, but when these conditions are concurrent with chronic headache, SA risk significantly increased (Table 4).

\section{Discussion}

In this largest study examining SA among veterans with different chronic pain disorders, we found that patients with chronic headache had a higher risk of SA than those with other chronic pains. Specifically, women with chronic headache are

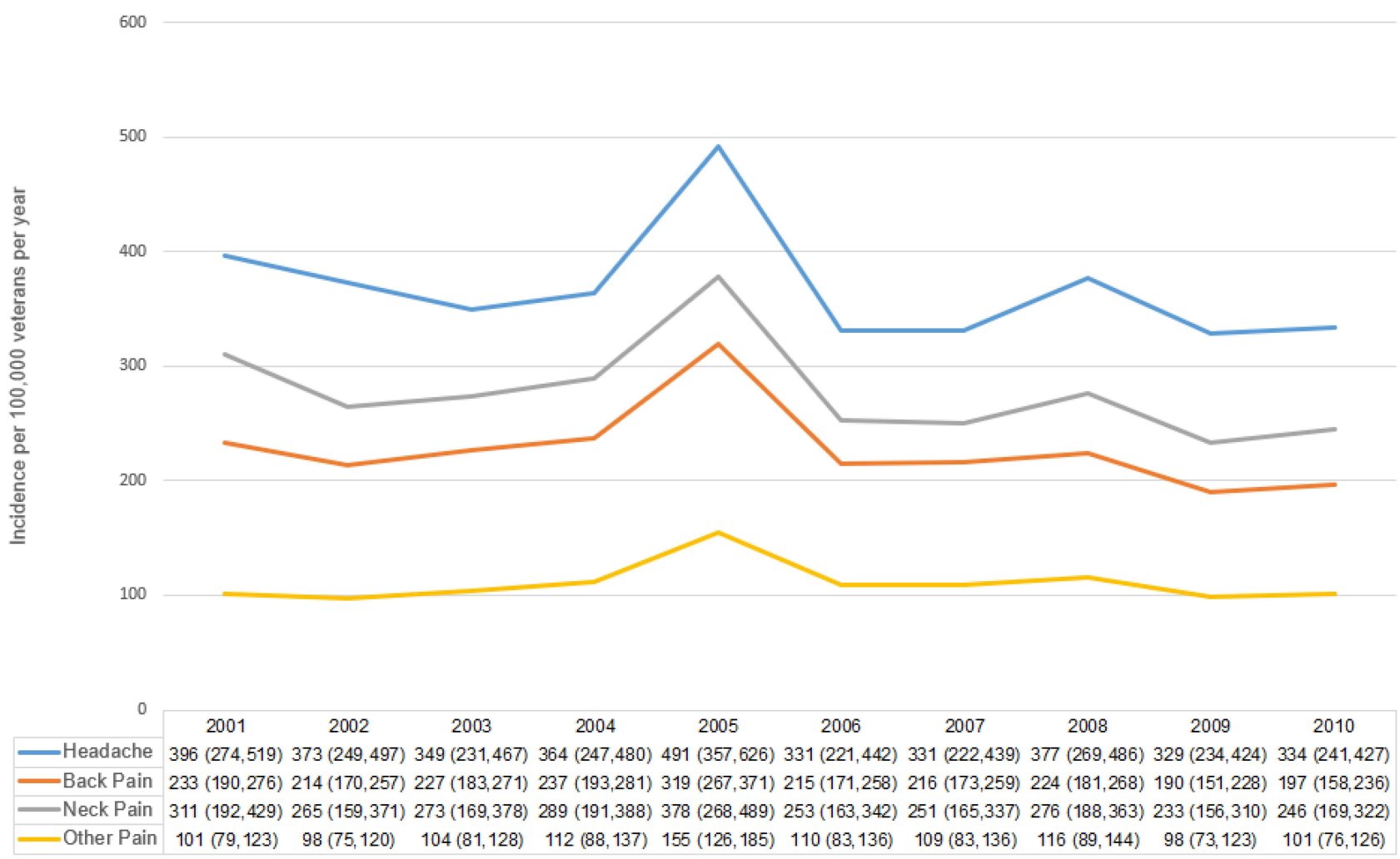

Figure 2 Incidence of suicide attempts for veterans with chronic pain (200I-20I0). 
Table 3 The Estimated Relative Risks of Suicide Attempts Using Poisson Regression Model in All Chronic Pain Patients

\begin{tabular}{|c|c|c|}
\hline & \multicolumn{2}{|c|}{ All Chronic Pain Veterans } \\
\hline Age at diagnosis & \multicolumn{2}{|c|}{$0.978(0.977,0.979) *$} \\
\hline Gender Male (Ref=Female) & \multicolumn{2}{|c|}{$1.33(1.3,1.36)^{*}$} \\
\hline \multicolumn{3}{|l|}{ Race (Ref=White) } \\
\hline Asian & \multicolumn{2}{|c|}{$1.64(1.49,1.8)^{*}$} \\
\hline Black & \multicolumn{2}{|c|}{$0.96(0.95,0.98)^{*}$} \\
\hline Unknown & \multicolumn{2}{|c|}{$0.78(0.75,0.8)^{*}$} \\
\hline \multicolumn{3}{|c|}{ Ethnicity (Ref=Not Hispanic/Latino) } \\
\hline Hispanic/Latino & \multicolumn{2}{|c|}{$0.88(0.86,0.91)^{*}$} \\
\hline Unknown & \multicolumn{2}{|c|}{$0.37(0.35,0.38)^{*}$} \\
\hline \multirow[t]{2}{*}{ Chronic Headache } & \multicolumn{2}{|c|}{$1.47(1.37,1.58)^{*}$} \\
\hline & Without occurrence of Headache & With occurrence of Headache \\
\hline \multirow[t]{2}{*}{ TBI } & $1.61(1.58,1.65)^{*}$ & $2.62(2.42,2.82)^{*}$ \\
\hline & \multicolumn{2}{|c|}{ Psychiatric Conditions: } \\
\hline Adjustment disorder & $1.58(1.55,1.61)^{*}$ & $2.31(2.15,2.49)^{*}$ \\
\hline Antisocial personality & $2.29(2.23,2.35)^{*}$ & $2.56(2.36,2.78)^{*}$ \\
\hline Anxiety & $0.96(0.94,0.99)^{*}$ & $1.55(1.43,1.67)^{*}$ \\
\hline ADHD & $1.16(1.1,1.21)^{*}$ & $1.83(1.67,2.01)^{*}$ \\
\hline Bipolar disorder & $2.86(2.81,2.92)^{*}$ & $3.42(3.17,3.69)^{*}$ \\
\hline Borderline personal & $2.5(2.44,2.57)^{*}$ & $4.21(3.89,4.56)^{*}$ \\
\hline Delusional disorder & $1.19(1.14,1.24)^{*}$ & $1.97(1.8,2.16)^{*}$ \\
\hline Dependent personality & $1.55(1.5,1.6 \mathrm{I})^{*}$ & $2.28(2.1,2.49)^{*}$ \\
\hline Depression & $4.76(4.62,4.91)^{*}$ & $8.21(7.89,8.55)^{*}$ \\
\hline Narcissistic personality & I.I $(1.06,1.15)^{*}$ & $1.78(1.63,1.95)^{*}$ \\
\hline OCD & $1.25(1.2,1.3)^{*}$ & $1.74(1.59,1.9)^{*}$ \\
\hline PTSD & $1.67(1.64,1.7)^{*}$ & $2.35(2.18,2.54)^{*}$ \\
\hline Schizoaffective disorder & $\mathrm{I} .37(\mathrm{I} .34, \mathrm{I} .4 \mathrm{I})^{*}$ & $1.72(1.58,1.87)^{*}$ \\
\hline Schizophrenia & $\mathrm{I} .45(\mathrm{I} .4 \mathrm{I}, \mathrm{I} .48)^{*}$ & $2.04(I .89,2.21)^{*}$ \\
\hline
\end{tabular}

Note:*Significant in level of 0.05 .

Abbreviations: PTSD, posttraumatic stress disorder; OCD, obsessive compulsive disorder; ADHD, Attention Deficit Hyperactivity Disorder.

at a higher risk than men. This is consistent with existing literature that women tend to attempt suicide more often than men, but men tend to die by suicide more than women. ${ }^{37}$ This differential in outcomes is largely due to the choice of method; that is, men tend to use more lethal means, such as firearms when attempting suicide, whereas women tend to methods, such as drug overdose. ${ }^{38}$ It is worth noting that overall veterans are more likely to use firearms in SA than the general population, and approximately $90 \%$ of SA by firearm result in death. ${ }^{39,40}$ In addition, we found that chronic headache concurrent with TBI heightened SA risk in both men and women, but the increased risk was more pronounced in men. In this cohort, men with chronic headache and TBI were almost three times more likely to have attempted suicide, whereas women were more than twice as likely to have attempted suicide. It is possible that higher suicide risk attempt in men with chronic headache and TBI is attributed to the severity of TBI and pain, and/or poor executive functioning associated with TBI, 
Table 4 The Estimated Relative Risks of Suicide Attempts Using Poisson Regression Model as Stratified by Sex

\begin{tabular}{|c|c|c|c|c|}
\hline & \multicolumn{2}{|c|}{ Male Chronic Pain Veterans } & \multicolumn{2}{|c|}{ Female Chronic Pain Veterans } \\
\hline Age at diagnosis & \multicolumn{2}{|c|}{$0.978(0.977,0.979)^{*}$} & \multicolumn{2}{|c|}{$0.978(0.976,0.98)^{*}$} \\
\hline \multicolumn{5}{|l|}{ Race (Ref=White) } \\
\hline Asian & \multicolumn{2}{|c|}{$1.43(1.28,1.59)^{*}$} & \multicolumn{2}{|c|}{$2.93(2.4 \mathrm{I}, 3.5 \mathrm{I})^{*}$} \\
\hline Black & \multicolumn{2}{|c|}{$0.99(0.97,1.01)$} & \multicolumn{2}{|c|}{$0.79(0.75,0.84)^{*}$} \\
\hline Unknown & \multicolumn{2}{|c|}{$0.76(0.73,0.78)^{*}$} & \multicolumn{2}{|c|}{$0.91(0.84,0.98)^{*}$} \\
\hline \multirow{2}{*}{\multicolumn{5}{|c|}{$\begin{array}{l}\text { Ethnicity (Ref=Not Hispanic/ } \\
\text { Latino) }\end{array}$}} \\
\hline & & & & \\
\hline Hispanic/Latino & \multicolumn{2}{|c|}{$0.86(0.83,0.89)^{*}$} & \multicolumn{2}{|c|}{$1.21(1.1,1.33)^{*}$} \\
\hline Unknown & \multirow{2}{*}{\multicolumn{2}{|c|}{$\begin{array}{l}0.38(0.36,0.39)^{*} \\
1.48(1.37,1.59)^{*}\end{array}$}} & \multirow{2}{*}{\multicolumn{2}{|c|}{$\begin{array}{l}0.3(0.25,0.35)^{*} \\
1.64(1.28,2.09)^{*}\end{array}$}} \\
\hline Chronic Headache & & & & \\
\hline & $\begin{array}{c}\text { Without occurrence of } \\
\text { Headache }\end{array}$ & $\begin{array}{c}\text { With occurrence of } \\
\text { Headache }\end{array}$ & $\begin{array}{c}\text { Without occurrence of } \\
\text { Headache }\end{array}$ & $\begin{array}{c}\text { With occurrence of } \\
\text { Headache }\end{array}$ \\
\hline \multirow[t]{2}{*}{ TBI } & $1.67(I .63,1.7 I)^{*}$ & $2.82(2.6,3.05)^{*}$ & I.I $(\mathrm{I} .0 \mathrm{I}, \mathrm{I} .2)^{*}$ & $2.16(1.67,2.78)^{*}$ \\
\hline & \multicolumn{4}{|c|}{ Psychiatric Conditions: } \\
\hline Adjustment disorder & $1.58(1.55,1.61)^{*}$ & $2.43(2.24,2.64)^{*}$ & $1.6(1.5 \mathrm{I}, \mathrm{I} .7)^{*}$ & $2.25(1.76,2.89)^{*}$ \\
\hline Antisocial personality & $2.43(2.37,2.5)^{*}$ & $2.66(2.44,2.91)^{*}$ & I.7I $(1.52,1.93)^{*}$ & $1.68(1.27,2.23)^{*}$ \\
\hline Anxiety & $0.99(0.97,1.01)$ & I.6 $(\mathrm{I} .47, \mathrm{I} .74)^{*}$ & $0.73(0.67,0.79)^{*}$ & $1.63(1.26,2.09)^{*}$ \\
\hline ADHD & $1.14(1.08,1.21)^{*}$ & $1.64(1.48,1.83)^{*}$ & $1.2(1.05,1.37)^{*}$ & $2.53(1.94,3.3)^{*}$ \\
\hline Bipolar disorder & $2.86(2.8,2.93)^{*}$ & $3.47(3.19,3.77)^{*}$ & $2.33(2.17,2.5 \mathrm{I})^{*}$ & $3.56(2.77,4.58)^{*}$ \\
\hline Borderline personal & $2.15(2.09,2.22)^{*}$ & $3.73(3.42,4.07)^{*}$ & $4.75(4.4 I, 5.1 \mathrm{I}) *$ & $7.8(6.05,10.07)^{*}$ \\
\hline Delusional disorder & $1.19(1.14,1.24)^{*}$ & $2.06(1.87,2.27)^{*}$ & $1.29(1.13,1.47)^{*}$ & $1.72(1.29,2.3)^{*}$ \\
\hline Dependent personality & $1.63(1.56,1.69)^{*}$ & $2.37(2.16,2.6)^{*}$ & $1.23(1.08,1.39)^{*}$ & $2.43(1.86,3.16)^{*}$ \\
\hline Depression & $4.68(4.54,4.83)^{*}$ & $8.47(8.12,8.84)^{*}$ & $6.34(5.34,7.6)^{*}$ & $7.78(6.49,9.33)^{*}$ \\
\hline Narcissistic personality & $1.12(1.07,1.16)^{*}$ & I.85 $(1.68,2.04)^{*}$ & $1.56(1.34, I .8 \mathrm{I})^{*}$ & $1.73(1.3,2.3)^{*}$ \\
\hline OCD & $1.28(1.22,1.33)^{*}$ & $1.75(1.59,1.94)^{*}$ & $1.02(0.9,1.15)$ & $2.07(1.59,2.69)^{*}$ \\
\hline PTSD & $1.63(1.6,1.66)^{*}$ & $2.27(2.1,2.46)^{*}$ & $2.03(1.89,2.17)^{*}$ & $2.89(2.25,3.72)^{*}$ \\
\hline Schizoaffective disorder & $1.39(1.35,1.43)^{*}$ & $1.75(1.6,1.92)^{*}$ & $1.25(1.14,1.37)^{*}$ & $1.83(1.41,2.37)^{*}$ \\
\hline Schizophrenia & $\mathrm{I} .47(\mathrm{I} .43, \mathrm{I} .5 \mathrm{I})^{*}$ & $2.03(1.86,2.21)^{*}$ & $1.29(1.18,1.42)^{*}$ & $2.2(1.7,2.84)^{*}$ \\
\hline
\end{tabular}

Note: $*$ Significant in level of 0.05 .

Abbreviations: PTSD, posttraumatic stress disorder; OCD, obsessive compulsive disorder; ADHD, Attention Deficit Hyperactivity Disorder.

whereas higher suicide risk in women with chronic headache alone is attributed to catastrophizing pain. Differences may also exist in social determinants of health, socio-economic factors, homeless status, sleep problems, hormonal changes, and other health issues that are difficult to evaluate using this administrative database.

Our study examined the annual incidence based on physician diagnosed SA in chronic head, neck, back and other pain over a decade time span. Each year, SA incidence was consistently the highest in those with chronic headache than any other non-headache chronic pain conditions. A transitory increase in SA was noted across all types of chronic pain conditions within 2005. The cause of this spike is unclear and may merit further investigation, but given that this spike was consistent across all chronic pain conditions, it is most likely a historical artifact unrelated to our research question (eg it is possible that the changes in deployment patterns or veteran resources may have contributed to this 
spike). As the present study looks only at medically confirmed SA within EHR data rather than broader community survey reports, it is likely that the rate of SA represented in this study is lower than previously reported. ${ }^{22}$ Not all SA result in medical interventions. Veterans may acknowledge intent more readily in an anonymous survey than directly to their health care provider; subsequently, some suicidal behaviors simply are never reported to medical providers. ${ }^{41}$ Clinicians may differ in their willingness to examine and ability to elicit intent to self-harm from patients who present for care. While suicide underreporting is a perennial problem in the field of suicide prevention, including only medically documented SA increases the internal validity of our findings.

Chronic headache is characterized by unique neurobiological and psychological factors that may distinctly contribute to suicide risk in veterans with TBI. Chronic head pain tends to be particularly debilitating even beyond the general experience of chronic pain, as it is uniquely characterized by a severe limitation of self-efficacy due to an associated sense of subjective helplessness. ${ }^{42}$ fMRI findings in patients with chronic migraine showed that higher headache frequency is associated with aberrant connectivity in Salience and Executive networks as well as intranet network connectivity. ${ }^{43,44}$ Chronic headache concurrent with TBI likely further compromises executive functioning and/or increases feelings of helplessness, while decreasing top-down inhibition of behavior. At the biomolecular level, we postulate that the etiopathogenic mechanism of SA in this population is associated with chronic, exacerbated neuroinflammatory process associated with both chronic headache/migraine, TBI, and SA. ${ }^{9}$

\section{Conclusion}

This is the largest retrospective VA study that afforded the opportunity to examine the impact of chronic headache and chronic headache concurrent with TBI on the SA risk in men and women, while accounting for demographic factors and psychiatric comorbidities. This study sheds new light on the higher risk of SA in veterans with chronic headache disorders with and without TBI, as compared to other chronic pain conditions. Specifically, women with chronic headache are at a higher risk than men, and chronic headache concurrent with TBI further increases SA risk, especially in men.

\section{Clinical Implication}

Necessary suicide screening precautions should be taken for veterans with chronic headache disorders with or without concurrent TBI. Even if chronic headache disorders are only a red flag, it is imperative for clinicians to attend to this as veterans typically speak more freely about headache than other symptoms, such as mental health issues. Veterans could also benefit from empathetic listening by clinicians when there is a lack of effective therapy for suicide prevention. We suspect that many of these patients with chronic headache disorders and TBI likely have undiagnosed chronic post-traumatic headache. Untreated or undertreated post-traumatic headache could further potentiate SA risk. Furthermore, our findings highlight the importance of addressing chronic head pain and TBI sequela. VA/DoD Best Practice recommends using multidisciplinary care approaches that integrate behavioral health care into the management of chronic pain and TBI. Cognitive Behavioral Therapy for Chronic Pain (CBT-CP) has been shown to improve quality of life for a variety of chronic pain conditions. Having behavioral health targeted for chronic headache and embedded into neurology or headache clinics could reduce barriers to care, such as transportation and referral delays. ${ }^{45-47}$ Lastly, given that chronic headache concurrent with TBI affected men more than women in $\mathrm{SA}$, additional resources for suicide prevention in male veterans with TBI and headache are warranted.

\section{Strengths and Limitations Strengths}

First, this longitudinal retrospective study examined an extremely large cohort of veterans with chronic pain over a decade. Very few studies have the power to examine risk for SA while stratifying for sex among patients with different types of chronic pain conditions. Second, utilizing physician verification of chronic pain, TBI, and SA offers enhanced confidence in identifying diagnosis as compared to using questionnaire-based survey.

\section{Limitations}

Our data lacked specificity regarding the duration and severity of chronic headache, TBI, and/or mental health conditions. We acknowledge that confounding variables such as life stress, psychological vulnerabilities (eg, hopelessness, impulsivity), sleep disturbance, concomitant medications, employment and marital status, and other social determinants of health may influence the associations between pain and suicidal behavior. Given that the comparison group in this analysis has other chronic pain conditions and not healthy control, it is less likely that the 
association we identified is spurious. The definition of chronicity using claim data may not always reflect the true characteristics of pain duration. For example, defining chronic headaches in this manner does not differentiate between a person who may have 2 headaches per month from someone who has more than 15 headaches per month. However, most likely those with persistent headache would have continued to follow up with their treating physicians. While this study captured medically confirmed $\mathrm{SA}, \mathrm{TBI}$, and chronic pain conditions using a broad range of ICD-9 codes, it is difficult to compile a completely comprehensive list of all possible ICD- 9 codes to capture all patients with SA and different chronic pain conditions. It should be noted that EHR was only examined from 2000 to 2010 , some veterans may have received a chronic pain diagnosis in years prior to this review, which could contribute to an underestimate of annual SA incidence at the beginning of the decade, the impact of this is likely low as we did not observe a significantly lower incidence in the first few years of the decade. In addition, patients who were lost to follow-up or chose to receive care outside the VHA system after their initial pain diagnoses were not included in our study. Finally, the use of physician verification for different types of pain, mental health, and SA may have resulted in underrepresentation. Historically, accurate reporting of suicide and suicide-related behaviors has been artificially low in most settings due to a number of factors including misclassification, fear and stigma, or a combination of factors. ${ }^{48-50}$ Caution should also be taken when generalizing studies on veterans to the civilian population. The veteran population is primarily comprised of males. Patients with the VHA tend to be of higher acuity than the civilian population due to their unique military or combat experiences contributing to their medical conditions. Despite these limitations, the present study highlights the importance of chronic headache disorders and $\mathrm{TBI}$ in increasing SA risk.

\section{Human and Animal Rights and Informed Consent}

This article does not include any studies with human or animal subjects performed by any of the authors.

\section{Acknowledgment}

We thank Dr. Guoshuai Cai for his assistance in editing the manuscript. The contents of this paper do not represent the views of the US Department of Veterans Affairs or the United States Government.

\section{Author Contributions}

All authors made a significant contribution to the work reported, whether that is in the conception, study design, execution, acquisition of data, analysis and interpretation, or in all these areas; took part in drafting, revising or critically reviewing the article; gave final approval of the version to be published; have agreed on the journal to which the article has been submitted; and agree to be accountable for all aspects of the work.

\section{Disclosure}

Dr B Lee Peterlin is a member of Speakers Bureau for Amgen, Biohaven, Lundbeck, Novartis, and AbbVie; also a member of the Advisory Board for Johnson \& Johnson, outside the submitted work. The authors report no other conflicts of interest in this work.

\section{References}

1. Erlangsen A, Stenager E, Conwell Y, et al. Association between neurological disorders and death by suicide in Denmark. JAMA. 2020;323(5):444-454. doi:10.1001/jama.2019.21834

2. Costanza A, Baertschi M, Weber K, Canuto A. Maladies neurologiques et suicide: de la neurobiologie au manque d'espoir [Neurological diseases and suicide: from neurobiology to hopelessness]. Rev Med Suisse. 2015;11(461):402-405.

3. Costanza A, Amerio A, Aguglia A, et al. When sick brain and hopelessness meet: some aspects of suicidality in the neurological patient. CNS Neurol Disord Drug Targets. 2020;19(4):257-263. doi:10.2174/ 1871527319666200611130804

4. Saylor D, Steiner TJ. The global burden of headache. Semin Neurol. 2018;38(2):182-190. doi:10.1055/s-0038-1646946

5. Simpson G, Tate R. Suicidality after traumatic brain injury: demographic, injury and clinical correlates. Psychol Med. 2002;32 (4):687-697. doi:10.1017/s0033291702005561

6. Fonda JR, Fredman L, Brogly SB, McGlinchey RE, Milberg WP, Gradus JL. Traumatic brain injury and attempted suicide among veterans of the wars in Iraq and Afghanistan. Am J Epidemiol. 2017;186(2):220-226. doi:10.1093/aje/kwx044

7. Silver JM, Kramer R, Greenwald S, Weissman M. The association between head injuries and psychiatric disorders: findings from the New Haven NIMH Epidemiologic Catchment Area Study. Brain Inj. 2001;15(11):935-945. doi:10.1080/02699050110065295

8. Teasdale TW, Engberg AW. Suicide after traumatic brain injury: a population study. J Neurol Neurosurg Psychiatry. 2001;71 (4):436-440. doi:10.1136/jnnp.71.4.436

9. Costanza A, Radomska M, Zenga F, et al. Severe suicidality in athletes with chronic traumatic encephalopathy: a case series and overview on putative ethiopathogenetic mechanisms. Int $J$ Environ Res Public Health. 2021;3:876.

10. Hostetter TA, Hoffmire CA, Forster JE, Adams RS, Stearns-Yoder KA, Brenner LA. Suicide and traumatic brain injury among individuals seeking veterans health administration services between fiscal years 2006 and 2015. J Head Trauma Rehabil. 2019;34:5. 
11. Tang NK, Crane C. Suicidality in chronic pain: a review of the prevalence, risk factors and psychological links. Psychol Med. 2006;36(5):575-586. doi:10.1017/s0033291705006859

12. Breslau N, Schultz L, Lipton R, Peterson E, Welch KMA. Migraine headaches and suicide attempt. Headache. 2012;52(5):723-731. doi:10.1111/j.1526-4610.2012.02117.x

13. Ilgen MA, Zivin K, McCammon RJ, Valenstein M. Pain and suicidal thoughts, plans and attempts in the United States. Gen Hosp Psychiatry. 2008;30(6):521-527. doi:10.1016/j. genhosppsych.2008.09.003

14. Ilgen MA, Kleinberg F, Ignacio RV, et al. Noncancer pain conditions and risk of suicide. JAMA Psychiatry. 2013;70(7):692-697. doi:10.1001/jamapsychiatry.2013.908

15. Kerns RD, Otis J, Rosenberg R, Reid MC. Veterans' reports of pain and associations with ratings of health, health-risk behaviors, affective distress, and use of the healthcare system. J Rehabil Res Dev. 2003;40(5):371-379. doi:10.1682/jrrd.2003.09.0371

16. Calati R, Laglaoui Bakhiyi C, Artero S, Ilgen M, Courtet P. The impact of physical pain on suicidal thoughts and behaviors: meta-analyses. J Psychiatr Res. 2015;71:16-32. doi:10.1016/j. jpsychires.2015.09.004

17. Kanzler KE, Bryan CJ, McGeary DD, Morrow CE. Suicidal ideation and perceived burdensomeness in patients with chronic pain. Pain Pract. 2012;12(8):602-609. doi:10.1111/j.1533-2500.2012.00542.x

18. Liu X, Liu ZZ, Yang Y, Jia CX. Prospective associations of frequent pain symptoms with suicidal behavior in adolescents. J Pain. 2021. doi:10.1016/j.jpain.2021.02.007

19. Pei JH, Wang XL, Yu Y, et al. Prevalence of suicidal ideation and suicide attempt in patients with migraine: a systematic review and meta-analysis. J Affect Disord. 2020;277:253-259. doi:10.1016/j. jad.2020.08.019

20. Ali SK, Soomar SM. Hopelessness leading to self-harm and suicide. J Neurol Neurosci. 2019;10:296.

21. Prevention OoMHaS. 2019 National Veteran Suicide Prevention Annual Report; 2019.

22. Ratcliffe GE, Enns MW, Belik SL, Sareen J. Chronic pain conditions and suicidal ideation and suicide attempts: an epidemiologic perspective. Clin J Pain. 2008;24(3):204-210. doi:10.1097/ AJP.0b013e31815ca2a3

23. Edwards RR, Smith MT, Kudel I, Haythornthwaite J. Pain-related catastrophizing as a risk factor for suicidal ideation in chronic pain. Pain. 2006;126(1):272-279. doi:10.1016/j.pain.2006.07.004

24. Racine M, Sánchez-Rodríguez E, Gálan S, et al. Factors associated with suicidal ideation in patients with chronic non-cancer pain. Pain Med. 2017;18(2):283-293. doi:10.1093/pm/pnw115

25. Haskell SG, Heapy A, Reid MC, Papas RK, Kerns RD. The prevalence and age-related characteristics of pain in a sample of women veterans receiving primary care. $J$ Womens Health (Larchmt). 2006;15(7):862-869. doi:10.1089/jwh.2006.15.862

26. Buse DC, Loder EW, Gorman JA, et al. Sex differences in the prevalence, symptoms, and associated features of migraine, probable migraine and other severe headache: results of the American Migraine Prevalence and Prevention (AMPP) Study. Headache. 2013;53(8):1278-1299. doi:10.1111/head.12150

27. Substance Abuse and Mental Health Services Administration. National Survey on Drug Use and Health: Quality Assessment of the 2002 to 2013 NSDUH Public Use Files; 2016.

28. Beautrais AL, Joyce PR, Mulder RT, Fergusson DM, Deavoll BJ, Nightingale SK. Prevalence and comorbidity of mental disorders in persons making serious suicide attempts: a case-control study. $\mathrm{Am}$ J Psychiatry. 1996;153(8):1009-1014. doi:10.1176/ajp.153.8.1009

29. Ravindran C, Morley SW, Stephens BM, Stanley IH, Reger MA. Association of suicide risk with transition to civilian life among US military service members. JAMA Net Open. 2020;3(9):e2016261. doi:10.1001/jamanetworkopen.2020.16261
30. Defrin R. Chronic post-traumatic headache: clinical findings and possible mechanisms. J Man Manip Ther. 2014;22(1):36-44. doi:10.1179/2042618613y.0000000053

31. Packard RC. Current concepts in chronic post-traumatic headache. Curr Pain Headache Rep. 2005;9(1):59-64. doi:10.1007/s11916005-0076-6

32. Lucas S. Post-traumatic headache. In: Diamond S, Cady R, Diamond M, Green M, Martin V, editors. Headache and Migraine Biology and Management. 1st ed. Academic Press; 2015:chap 13.

33. Metti A, Schwab K, Finkel A, et al. Posttraumatic vs nontraumatic headaches: a phenotypic analysis in a military population. Neurology. 2020;94(11):e1137-e1146. doi:10.1212/wnl.00000000 00008935

34. Lipton RB, Diamond S, Reed M, Diamond ML, Stewart WF, Diagnosis M. Treatment: results from the American Migraine Study II. Headache. 2001;41(7):638-645. doi:10.1046/j.1526-4610.20 01.041007638.x

35. Noël PH, Copeland LA, Perrin RA, et al. VHA Corporate Data Warehouse height and weight data: opportunities and challenges for health services research. $J$ Rehabil Res Dev. 2010;47(8):739-750. doi:10.1682/jrrd.2009.08.0110

36. Price LE, Shea K, Gephart S. The veterans affairs's corporate data warehouse: uses and implications for nursing research and practice. Nurs Adm Q. 2015;39(4):311-318. doi:10.1097/naq.000000000 0000118

37. Schrijvers DL, Bollen J, Sabbe BG. The gender paradox in suicidal behavior and its impact on the suicidal process. $J$ Affect Disord. 2012;138(1-2):19-26. doi:10.1016/j.jad.2011.03.050

38. Freeman A, Mergl R, Kohls E, et al. A cross-national study on gender differences in suicide intent. BMC Psychiatry. 2017;17(1):234. doi:10.1186/s12888-017-1398-8

39. Conner A, Azrael D, Miller M. Suicide case-fatality rates in the United States, 2007 to 2014: a Nationwide Population-Based Study. Ann Intern Med. 2019;171(12):885-895. doi:10.7326/m191324

40. U.S Department of Veterans Affairs. 2020 National Veteran Suicide Prevention Annual Report. 2021

41. Richards JE, Whiteside U, Ludman EJ, et al. Understanding why patients may not report suicidal ideation at a health care visit prior to a suicide attempt: a qualitative study. Psychiatr Serv. 2019;70 (1):40-45. doi:10.1176/appi.ps.201800342

42. Greene NR, Smith CV, Jewell DE, Smitherman TA, Diary A. Study of basic psychological needs and daily headache experience. Headache. 2018;58(4):581-588. doi:10.1111/head.13273

43. Androulakis XM, Krebs K, Peterlin BL, et al. Modulation of intrinsic resting-state fMRI networks in women with chronic migraine. Neurology. 2017;89(2):163-169. doi:10.1212/wnl.0000000000 004089

44. Androulakis XM, Krebs KA, Jenkins C, et al. Central executive and default mode network intranet work functional connectivity patterns in chronic migraine. J Neurol Disord. 2018;6:5. doi:10.4172/23296895.1000393

45. Brunet K, Birchwood M, Lester H, Thornhill K. Delays in mental health services and duration of untreated psychosis. Psychiatric Bull. 2007;31:408-410. doi:10.1192/pb.bp.106.013995

46. Stewart MO, Karlin BE, Murphy JL, et al. National dissemination of cognitive-behavioral therapy for chronic pain in veterans: therapist and patient-level outcomes. Clin J Pain. 2015;31(8):722-729. doi:10.1097/ajp.0000000000000151

47. Syed ST, Gerber BS, Sharp LK. Traveling towards disease: transportation barriers to health care access. J Community Health. 2013;38 (5):976-993. doi:10.1007/s10900-013-9681-1

48. Calear AL, Batterham PJ. Suicidal ideation disclosure: patterns, correlates and outcome. Psychiatry Res. 2019;278:1-6. doi:10.1016/ j.psychres.2019.05.024 
49. Carroll R, Hawton K, Kapur N, Bennewith O, Gunnell D. Impact of the growing use of narrative verdicts by coroners on geographic variations in suicide: analysis of coroners' inquest data. $J$ Public Health (Oxf). 2012;34(3):447-453. doi:10.1093/pubmed/fdr091
50. Pritchard C, Hansen L. Examining undetermined and accidental deaths as source of 'under-reported-suicide' by age and sex in twenty Western countries. Community Ment Health J. 2015;51(3):365-376. doi:10.1007/s10597-014-9810-z

\section{Publish your work in this journal}

The Journal of Pain Research is an international, peer reviewed, open access, online journal that welcomes laboratory and clinical findings in the fields of pain research and the prevention and management of pain. Original research, reviews, symposium reports, hypothesis formation and commentaries are all considered for publication. The manuscript

Submit your manuscript here: https://www.dovepress.com/journal-of-pain-research-journa management system is completely online and includes a very quick and fair peer-review system, which is all easy to use. Visit http:// www.dovepress.com/testimonials.php to read real quotes from published authors. 